\title{
Being Together Apart: Does Communication via Social Media Help or Harm Romantic Relationships?
}

\author{
Mark Turner ${ }^{10000-0001-9072-9708]}$ and Emma Prince ${ }^{1}$ \\ ${ }^{1}$ Department of Psychology, University of Portsmouth, Portsmouth, United Kingdom \\ Mark. Turnereport.ac.uk \\ Emma.Princel@myport.ac.uk
}

\begin{abstract}
Social media has become central to how people form and maintain friendships and romantic relationships, although its effects are not always positive. The current study investigates how social media use impacts satisfaction in three different types of romantic relationships: (i) long-distance relationships, (ii) geographically close relationships, and (ii) couples living together. How young adults communicate with their partner via social media, the shared behaviors they exhibit and their association with the support, conflict, and relationship depth they experience are explored. Responses from 236 participants aged between $18-25$ years $(\mathrm{M}=20.68, \mathrm{SD}=1.83)$ were obtained. Complex associations were found between perceived relationship quality and different indices of shared social media behaviors. Findings provide partial support for the idea that social media platforms may provide an effective mechanism to support and maintain long-distance romantic relationships. However, the overall frequency of social media use was not an important factor in maintaining a satisfying relationship, whether couples were long-distance, geographically close or living together. In addition, greater social media use was not predictive of reduced relationship conflict in any form of relationship. Paradoxically, engaging in social media based surveillance behaviors was related to a higher sense of relationship depth. Those in long distance relationships used social media more for direct communication with a partner, but this also correlated with greater levels of relationship conflict.
\end{abstract}

Keywords: Social media, Romantic relationships, Conflict, Support, Surveillance.

\section{Introduction}

\subsection{Background and Aims}

Social media use has grown rapidly in popularity, with young adults becoming particularly dependent on its use [16]. One of the primary justifications for using social media is to keep in contact with those whom we already share relationships with [6] although the influence of communication via social media on friendships and roman- 
tic relationships may not always be positive [e.g. 27]. The development of romantic relationships plays a significant part in many young adults' lives, and it is common for such relationships to often involve some form of geographical separation [23]. It has been suggested that couples in long-distance relationships experience more stress compared to those who live geographically closer together [11]. It is therefore, important to understand the factors that may contribute to the maintenance of successful distance relationships in young adults and how social media in particular, may facilitate to this.

The potential value of the Internet to relationship formation and development has long been recognized [9]. More recently, the easy and ubiquitous access afforded by mobile devices to multiple, different social media platforms has set new expectations regarding communication patterns between romantic partners [15]. Whilst the prevalence of distance relationships has become increasingly common in modern society as individuals seek employment or educational opportunities in different locations, the use of technology by romantic partners may provide an important means by which behaviors that help maintain relationships can be conveyed [2].

Being in a long-distance relationship per se may not necessarily lead to great relationship dissatisfaction [10, 20, 24]. However, Holt and Stone [14] report that couples who spend longer periods of time apart and share lower quality verbal communication were found to experience poorer levels of relationship satisfaction. Whether the increased opportunities for domestic contact afforded by social media technology might offset this effect for geographically distance couples is however, not clear. Hampton, Rawlings, Treger and Sprecher [13] acknowledge a lack of research investigating how technology can help maintain satisfying romantic relationships. In their study of purely long-distance relationships, they found that individuals who used a greater variety of different computer-mediated communication channels experienced greater communication satisfaction, with the use of video-based chat applications being the strongest predictor of overall relationship satisfaction. Turner, Love and Howell [28] demonstrated that voice-based rather than text-based forms of communication were more important in reducing the discrepancy between desired and actual levels of emotional support in close relationships. It follows that relationship satisfaction is not simply a function of geographical distance but will also be dependent on the quality of mediated interaction within a relationship. The specific functionality supported by different social media platforms, and how couples choose to use these platforms may therefore, be important in determining the level of support and relationship depth that couples perceive.

Traditional media choice theories, assume that people choose a medium which best fits with their intended communication purpose, and that richer communication media should be preferred in the case of the maintenance of long-distance friendships where these make it easier to express and perceive emotions and provide feedback [29]. However, many aspects of social media-based communication between partners can also take place publically rather than through direct personal contact such that other 
social dimensions need to be taken into consideration. For example, Stewart, Dainton, and Goodboy [25] have demonstrated that where partners perceived a greater sense of relationship security they were more likely to engage in online reassurance behaviors, such as posting or commenting on their partner's social media profile. But, where partners perceived greater relationship uncertainty, they were more likely to engage in online monitoring of their partners. Greater partner surveillance behaviors were also linked to increased relational jealousy. This effect has been explained by the observation that social media sites sometimes expose people to potentially ambiguous information about their partner which they would not otherwise have access to, which motivates further social media use and partner surveillance [18]. Since social media makes the surveillance of a romantic partner relatively easy and anonymous [26], it exposes individuals to aspects of their partner's communication with others that arouses feelings of protectiveness or suspicion over their shared relationship, which in the absence of other cues, may be particularly relevant to the feelings experienced in long-distance relationships [3].

Further evidence suggests that where online displays of affection are valued by a partner, these can strengthen a romantic relationship [8]. Several methods through which affection can be displayed via social media have been identified [17] including through the use of features such as relationship status updates, displaying pictures showing shared experiences with a partner, and public commenting on a partner's activities which allow the nature of one's relationship to be declared and vicariously communicated to others. Such mechanisms can be used to emphasize possession and territory, as well as to validate the status of a relationship [4].

Given the complex and still developing channels by which social media may impact on relationships, the current study set out to explore and compare social media use and its links to relationship satisfaction in three different types of partnerships: (i) long-distance relationships (LDR), (ii) couples living apart but with geographically close relationships (GCR) and (iii) cohabiting couples (CC). The study focuses particularly on comparing the shared behaviors used by young adults when communicating with their partners and how they perceive the importance of social media within relationships of different types. Two specific research questions are explored:

Research Question 1: How does the specific nature of social media use in romantic relationships at different geographical distances differ, and what are the consequences of these differences for the relationship support and depth, and conflict experienced?

Research Question 2: How does the perceived importance of social media as facilitating relationship quality vary in relationships at different geographical distances? 


\section{$2 \quad$ Method}

\subsection{Participants and Design}

A total of 273 participants were purposively recruited by means of an online survey; all participants were required to be currently in a relationship and actively using social media to communicate with their partner. Participants aged over 25 years, participants who were married, or those who gave incomplete survey responses were screened out, leaving a final sample size of 236 participants.

The study used a quasi-experimental design, whereby participants were naturally separated into three groups: (i) long-distance relationships (LDR, n=66), (ii) geographically close relationships (GCR, $n=123$ ) and (iii) cohabiting couples $(C C, n=47)$. Relationship distance was determined based upon the self-categorization approach used in previous research [9]. The geographical distance between the permanent home addresses of the participant and their partner was also recorded, which confirmed LDR participants lived on average 154.9 miles from their partner, and GCR participants lived on average 10.7 miles from their partner $(t(176)=10.49, p<.001 ; d=1.58)$.

The final sample included 180 females and 56 males, with a mean age of 20.68 years $(\mathrm{SD}=1.83)$. Participants' mean self-rated level of social media use for communicating with their partner (on a 10-point scale, where 10 indicated greater use) was $7.97(\mathrm{SD}=2.45)$, and the mean length of their relationship with their partner was 2.30 years $(\mathrm{SD}=2.08)$.

\subsection{Measures}

Social Media Use and Behaviors. Participants were asked a series of questions about the frequency and variety of social media platforms they used to communicate with their partner, and completed assessments of the specific online behaviors they engaged in with their partner and their views of its importance to their relationship.

Shared Social Media Behaviors. A total of 20 different shared online behaviors were identified from existing literature which were used to provide a profile of how each participant communicated with their partner online. Participants were asked to rate how regularly they adopted each behavior (e.g. Tag them in a picture) or used embedded social media tools or features to engage their partner (e.g. Send a voice note to each other). Each item was rated on a 4-point frequency scale from 'Not At All' to 'Very Much'.

Importance of Social Media. A further 14 questionnaire items were created to assess how each individual felt about the use and importance of social media within their relationship to communicate with their partner. Each statement (e.g. I believe social 
media helps my partner and I to share common interests) was rated using the same 4point scale from 'Not At All' to 'Very Much'.

Relationship Quality. The 25-item Quality of Relationships Inventory [19] was used to assess how satisfied participants were in their current relationship. Questions such as, 'How significant is this person in your life?' and 'To what extent can you turn to this person for advice about problems?' are rated on a 4-point scale from 'Not At All' to 'Very Much'. The QRI specifically measures three aspects of relationship quality: Perceived Social Support (PSS, 7 items), Relationship Conflict (RC, 12 items), and Relationship Depth (RD, 6 items). Pierce et al. [19] report Cronbach's alpha coefficients for the three subscales to range between 0.83 and 0.91 . In addition to their relationship duration, participants were also asked how many days per week they typically met their partner face-to-face.

\subsection{Procedure}

Participants were informed that the research would investigate social media use within romantic relationships but were not told the study was focused on relationship distance specifically. The survey took between 15-20 minutes to complete. Question sections were presented in the same order to all participants, with questions about social media use and behavior being presented before questions about relationship quality. The study was conducted in accordance with the appropriate ethical guidelines and approval process of our institution.

\section{Results}

\subsection{Shared Social Media Behaviors}

The extent to which romantic partners engaged in different social media behaviors varied considerably across the 20 activities examined (Table 1). Sending messages and pictures directly to each other and also showing each other social media posts when being physically together appeared to be the most universally experienced activities. Liking a partner's picture or tagging them in a picture were also common amongst respondents.

A Factor Analysis using oblique rotation was performed on the 20 social media behaviors to explore latent patterns in participants' responses. A three factor solution was extracted using PCA which was confirmed by parallel analysis as being the most appropriate solution for the data (Minimum random Eigenvalue = 1.55, KMO =.76). Factor I consisted of questions related to the monitoring of a partner's online behavior without their knowledge. The factor, which accounted for $22.5 \%$ of the variance in responses, loaded most heavily on questions such as checking who a partner was following or who was following them, and viewing who had liked their posts. This factor was named 'Surveillance Behaviors'. 
Factor II accounted for $12.7 \%$ of the variance in responses and predominately clustered together questions which involved active, shared experiences that occurred directly between partners and that were not accessible to others. This factor included behaviors such as sharing a video chat or sending pictures directly to each other, and so was named 'Direct Communication'.

Factor III accounted for $8.9 \%$ of variance in responses and largely grouped together behaviors that would be visible to others outside of the relationship such as posting a message publically about a partner, and liking or commenting on their pictures. The factor was therefore, named 'Public Displays of Contact'. Since all items loaded negatively on this factor, indicating the factor rotation aligned with an absence of these behaviors, all question items were reverse scored before calculating the scale total, so that a higher factor total corresponded to a greater tendency to engage in public displays of contact in the subsequent analyses reported.

Table 1. Factor loadings for participants' social media behaviors towards their partners and percentage of respondents engaging in each behavior. Values in bold indicate parent factor.

\begin{tabular}{|c|c|c|c|c|}
\hline \multirow{2}{*}{ Social Media Behaviour } & \multirow{2}{*}{$\begin{array}{c}\text { Participants } \\
\text { engaging in } \\
\text { behaviour } \\
(\%)\end{array}$} & \multicolumn{3}{|c|}{ Factor Loadings } \\
\hline & & $\begin{array}{c}\text { Factor } \\
\text { I }\end{array}$ & $\begin{array}{c}\text { Factor } \\
\text { II }\end{array}$ & $\begin{array}{c}\text { Factor } \\
\text { III }\end{array}$ \\
\hline Check who is following them & $38.1 \%$ & .85 & -.19 & -.08 \\
\hline Check who they are following & $41.5 \%$ & .84 & -.18 & -.08 \\
\hline View who has liked their pictures & $42.4 \%$ & .75 & -.14 & -.23 \\
\hline View pictures they have liked & $55.5 \%$ & .64 & -.08 & -.12 \\
\hline Check your partners social media page & $73.3 \%$ & .64 & .13 & -.22 \\
\hline Check when your partner is online & $66.9 \%$ & .45 & .39 & .11 \\
\hline Use partner's social media without them knowing & $3.8 \%$ & .44 & .43 & .26 \\
\hline Share a video chat & $72.0 \%$ & -.07 & .60 & -.06 \\
\hline Send a picture to each other & $97.5 \%$ & .01 & .59 & -.28 \\
\hline Send a message to each other & $98.7 \%$ & -.23 & .53 & -.24 \\
\hline Send a voice note to each other & $35.2 \%$ & -.12 & .53 & .06 \\
\hline Check your partner's location & $45.3 \%$ & .27 & .40 & .02 \\
\hline Use partner's social media with them knowing & $19.9 \%$ & .33 & .40 & .14 \\
\hline Send them a link & $73.7 \%$ & -.12 & .35 & -.24 \\
\hline Comment on their picture & $79.7 \%$ & .11 & .06 & -.73 \\
\hline Like their picture & $94.9 \%$ & .19 & .07 & -.73 \\
\hline Tag them in a picture & $89.4 \%$ & -.05 & .13 & -.67 \\
\hline Post about your partner & $84.7 \%$ & -.05 & .13 & -.67 \\
\hline View your partners 'stories' & $87.3 \%$ & .00 & -.01 & -.63 \\
\hline Show partner social media posts when together & $97.5 \%$ & .06 & -.10 & -.43 \\
\hline Factor Eigenvalue & & 4.50 & 2.54 & 1.79 \\
\hline
\end{tabular}




\subsection{Importance of Social Media to Relationships}

To evaluate participants' attitudes towards the use of social media to support different aspects of communication and engagement with their partners, a Factor Analysis with oblique rotation was performed on the 14 attitude statements assessing the importance of social media in relationships (Table 2). A three factor solution was extracted using PCA which was confirmed by parallel analysis as being the most appropriate solution for the data (Minimum random Eigenvalue $=1.43, \mathrm{KMO}=.79$ ).

Table 2. Factor loadings for perception of social media importance to relationships items and percentage of participants reporting each attitude. Values in bold indicate parent factor.

\begin{tabular}{|c|c|c|c|c|}
\hline \multirow{2}{*}{ Attitude Component } & \multirow{2}{*}{$\begin{array}{l}\text { Participants } \\
\text { reporting } \\
\text { attitude } \\
(\%)\end{array}$} & \multicolumn{3}{|c|}{ Factor Loadings } \\
\hline & & $\begin{array}{l}\text { Factor } \\
\text { I }\end{array}$ & $\begin{array}{l}\text { Factor } \\
\text { II }\end{array}$ & $\begin{array}{l}\text { Factor } \\
\text { III }\end{array}$ \\
\hline $\begin{array}{l}\text { I feel unappreciated when my partner does not post } \\
\text { pictures of me on social media }\end{array}$ & $42.4 \%$ & .77 & -.02 & .15 \\
\hline $\begin{array}{l}\text { I feel jealous seeing my partner like other people's } \\
\text { pictures }\end{array}$ & $34.3 \%$ & .77 & -.06 & -.17 \\
\hline $\begin{array}{l}\text { I feel paranoid seeing who my partner follows on } \\
\text { social media }\end{array}$ & $24.2 \%$ & .72 & -.01 & -.17 \\
\hline I obsess over checking my partner's social media & $14.8 \%$ & .71 & -.21 & -.15 \\
\hline $\begin{array}{l}\text { I am disappointed when my partner does not com- } \\
\text { ment on or like my pictures }\end{array}$ & $56.4 \%$ & .67 & .06 & .22 \\
\hline $\begin{array}{l}\text { My partner posting about me on social media helps } \\
\text { me to feel like I am more included in their life }\end{array}$ & $73.7 \%$ & .62 & .23 & .21 \\
\hline $\begin{array}{l}\text { If I see my partner is active on social media but has } \\
\text { not contacted me, I feel annoyed }\end{array}$ & $57.2 \%$ & .56 & .25 & -.05 \\
\hline $\begin{array}{l}\text { Sending my partner messages on social media } \\
\text { makes me feel closer to them }\end{array}$ & $89.0 \%$ & .10 & .81 & .10 \\
\hline $\begin{array}{l}\text { I believe social media helps my partner and I to } \\
\text { communicate more efficiently }\end{array}$ & $88.1 \%$ & -.02 & .79 & .22 \\
\hline $\begin{array}{l}\text { Social media helps my partner and I to share com- } \\
\text { mon interests }\end{array}$ & $93.6 \%$ & .08 & .74 & .00 \\
\hline $\begin{array}{l}\text { I do not feel the need to socialize with my partner } \\
\text { on social media }\end{array}$ & $56.8 \%$ & .06 & -.61 & .34 \\
\hline $\begin{array}{l}\text { Social media does not adversely affect my relation- } \\
\text { ship with my partner }\end{array}$ & $73.3 \%$ & -.09 & -.07 & .75 \\
\hline $\begin{array}{l}\text { It does not bother me seeing my partner communi- } \\
\text { cate with somebody online that I do not know }\end{array}$ & $64.0 \%$ & .14 & -.06 & .68 \\
\hline $\begin{array}{l}\text { I feel happy seeing my partner post pictures online } \\
\text { with other people, as I know they are having fun }\end{array}$ & $94.5 \%$ & -.14 & .22 & .53 \\
\hline Factor Eigenvalue & & 3.69 & 2.45 & 1.48 \\
\hline
\end{tabular}


Factor I accounted for $26.4 \%$ of the variance in participants' responses and loaded most heavily on questions relating to feeling unappreciated, jealous or paranoid about their partner's behavior on social media. This factor was named 'Online Jealousy' (7 items). Factor II comprised questions which related to the positive benefits of using social media to communicate with their partner such as increased closeness, sharing interests and efficiency of support, and accounted for $17.5 \%$ of the variance in responses. This factor was named 'Relationship Facilitation' (4 items). Factor III accounted for $10.6 \%$ of the variance in participants' responses and consisted of questions which indicated participants felt social media had no bearing on their relationship, or that they were unaffected by or felt benevolent towards their partners social media behavior. This factor was named 'Online Disinterest' ( 3 items).

Online jealousy correlated strongly and positively with social media surveillance behaviors $(r(234)=.58, p<.001)$, but was not related to the use of social media for direct communication. Online jealousy also correlated negatively with public shows of contact via social media $(r(234)=-.29, p<.001)$. Relationship facilitation correlated positively with the use of social media for direct communication $(r(234)=.41$, $p<.001)$ and correlated negatively with public shows of contact via social media $(r(234)=-.29, p<.001)$ but was not related to surveillance behaviors. Online Disinterest was weakly correlated to the use of social media for direct communication $(r(234)=.18, p=.006)$ and was not related to surveillance behaviors or public shows of contact between partners.

\subsection{Social Media Use and Attitude Differences by Relationship Distance}

To compare differences in online behaviors and perceptions regarding the importance of social media within relationships as a function of geographical distance between partners, a one-way multivariate analysis of covariance was performed, with length of relationship as a covariate (Table 3 ).

Table 3. Mean ( \pm 1 SD) subscale totals for social media behaviors and perception of importance of social media to relationships as a function of relationship type.

\begin{tabular}{|c|c|c|c|c|c|c|c|c|c|}
\hline \multirow{3}{*}{$\begin{array}{l}\text { Social Media Behav- } \\
\text { iours and Attitudes } \\
\text { Surveillance Behaviors }\end{array}$} & \multicolumn{6}{|c|}{ Relationship Type } & \multirow{3}{*}{$\begin{array}{c}\mathrm{F} \\
.55\end{array}$} & \multirow{3}{*}{$\begin{array}{c}\mathrm{p} \\
.58\end{array}$} & \multirow{3}{*}{$\begin{array}{c}\eta^{2} \\
.01\end{array}$} \\
\hline & \multicolumn{2}{|c|}{$\mathrm{CC}$} & \multicolumn{2}{|c|}{ GCR } & \multicolumn{2}{|c|}{ LDR } & & & \\
\hline & 1.76 & $(0.65)$ & 1.73 & $(0.67)$ & 1.64 & $(0.64)$ & & & \\
\hline Direct Communication & $2.24^{\mathrm{a}}$ & $(0.54)$ & $2.58^{\mathrm{a}}$ & $(0.54)$ & $2.78^{\mathrm{a}}$ & $(0.43)$ & 15.09 & $<.001$ & .12 \\
\hline Public Displays & $2.11^{\mathrm{a}}$ & $(0.75)$ & 2.20 & $(0.64)$ & $2.41^{\mathrm{a}}$ & $(0.70)$ & 3.20 & .04 & .03 \\
\hline Online Jealousy & 1.56 & $(0.52)$ & 1.63 & $(0.57)$ & 1.69 & $(0.52)$ & 0.83 & .44 & .01 \\
\hline Relationship Facilitation & $2.51^{\mathrm{a}}$ & $(0.55)$ & $2.84^{\mathrm{a}}$ & $(0.68)$ & $3.17^{\mathrm{a}}$ & $(0.61)$ & 13.81 & $<.001$ & .11 \\
\hline Online Disinterest & 2.57 & $(0.66)$ & 2.51 & $(0.73)$ & 2.59 & $(0.73)$ & 0.35 & .70 & .00 \\
\hline $\begin{array}{l}\text { Frequency of Social } \\
\text { Media Partner Contact }\end{array}$ & $6.94^{\mathrm{a}}$ & $(2.97)$ & $7.89^{\mathrm{b}}$ & $(2.42)$ & $8.85^{\mathrm{ab}}$ & $(1.68)$ & 9.10 & $<.001$ & .07 \\
\hline
\end{tabular}

${ }^{\mathrm{ab}}$ Group means with the same letter differ significantly at $p<.05$ (Bonferroni comparisons). 
A significant multivariate effect was found between the three relationship groups $\left(F(14,454)=5.38, p<.001, \eta^{2}{ }^{2}=.14\right.$, Wilks' $\left.\lambda=0.72\right)$. Significant univariate differences were found for 3 of the subscale measures. Results indicated that participants in longdistance relationships were more likely to use social media for direct communication with their partner and overt public displays of contact with their partner, when compared to other relationship types. The perception of social media as a relationship facilitator also differed as a function of geographical distance between partners, with participants in long-distance relationships regarding social media as being more beneficial than those in geographical close relationships or those who lived together. The frequency with which participants used social media to contact their partners also differed significantly as a function of geographical distance; those in long-distance relationships used social media to communicate more frequently with their partners compared to those in other relationship types. However, there was no difference in the frequency of social media communication between those in geographically close relationships or those who lived together.

\subsection{Correlations Between Social Media Behaviors, Perceptions of Social Media Importance and the Quality of Relationships}

Pearson correlation coefficients were calculated to explore the relationships between social media behaviors, attitudes towards the importance of social media within relationships and the QRI measure of relationship quality (Table 4).

Table 4. Pearson's Correlations between Social Media Behaviors, Attitudes towards the Importance of Social Media, Partner Contact and Relationship Quality.

\begin{tabular}{lccc}
\hline \multirow{2}{*}{ Social Media Behaviours and Attitudes } & \multicolumn{2}{c}{ Quality of Relationship (QRI) } \\
\cline { 2 - 4 } & Support & Conflict & Depth \\
\hline Surveillance Behaviors & $.14^{*}$ & -.01 & $.23^{* *}$ \\
Direct Communication & $.16^{*}$ & $.16^{*}$ & -.04 \\
Public Displays of Contact & $-.21 * *$ & $-.14^{*}$ & -.04 \\
Online Jealousy & .08 & -.04 & $.32^{* *}$ \\
Relationship Facilitation & .08 & $.16^{*}$ & -.01 \\
Online Disinterest & .03 & $.17 * *$ & $-.18^{* *}$ \\
Frequency of Face-to-Face Partner Contact & .06 & .04 & .05 \\
Frequency of Social Media Partner Contact & .08 & .08 & .04 \\
\hline
\end{tabular}

$* p<.05, * * p<.01$ (2-tailed)

Significant positive correlations were found between surveillance behaviors with relationship support and depth, suggesting participants who reported engaging in greater monitoring of their partner online also experienced a greater sense of relationship support and deeper more meaningful relationships. Greater use of social media 
for direct, personal communication between partners was associated with a greater perception of relationship support, but also greater relationship conflict. Whereas greater public displays of contact between partners was associated with reduced relationship conflict, but also a reduced sense of support.

Somewhat paradoxically, participants who reported experiencing feelings of jealousy as a result of their partner's behavior online reported greater relationship depth. However, the belief that social media facilitated relationships showed no correlation with relationship support or depth, but was related to greater relationship conflict. Those who believed social media played no role in their relationship (online disinterest) also reported greater relationship conflict and reduced relationship depth. No significant correlations were found between either the frequencies of face-to-face or social media contact reported by participants with their partners and any aspect of relationship quality.

\section{DISCUSSION}

The current study identified three common patterns of social media behaviors reported by those in romantic relationships: surveillance without a partner's knowledge; direct private communication between partners; and indirect public displays of contact to communicate partnerships that are visible to others. The study also identified three consistent attitudes in the responses of participants regarding the perceived importance of social media to their relationships: the belief that social media positively facilitates relationships, the belief that social media has no real bearing on relationships with partners, and the belief that social media use invokes feelings of jealousy and relationship insecurity. Several patterns emerged where online jealousy was more strongly associated with social media surveillance, whilst the belief that social media facilitated relationships was more strongly associated with more direct, private communication. Public displays of contact between partners were associated with reduced relationship facilitation, but also reduced jealousy.

With respect to the geographical distance between partners, LDR participants were found to communicate more frequently with their partner via social media, were more likely to use direct private communications and were more likely to believe social media facilitated their relationship than GCR participants or CC participants. LDR participants also engaged in more public displays of contact between partners than CC participants, but not GCR participants. Since direct communication between partners was associated with greater perceived relationship support, this may be taken as partial evidence to support the idea that communication via social media is beneficial to long-distance relationships. However, it should be noted that greater direct communication, and the belief that social media helps to facilitate relationships were also both associated with increased relationship conflict. Public displays of contact between partners, which were greatest in LDR participants were also associated with lower 
perceived relationship support. It follows that not all aspects of online behavior used by individuals to communicate with their partners in distance relationships may improve relationship satisfaction.

One explanation for these seemingly contradictory findings could be the assumption that increased online communication invariably creates positive outcomes. Braiker and Kelley [5] argue that couples who are more interdependent also tend to experience greater conflict within their relationship. With constant access to social media, it is possible that individuals can also use direct communication to send more harmful messages. Contextually less rich forms of communication such as those provided by social media may also provide couples with greater opportunities to miscommunicate or misinterpret intentions, or to prolong previous arguments online. Consistent with this view, Coyne et al. [8] found that individuals who perceived their relationship to be more satisfying used social media in order to express affection towards their partner, whereas those who were less satisfied with their relationship were more likely to use social media for the purposes of confrontation.

Zhao, Sosik, and Cosley [30] propose that public displays of affection do not have the purpose of benefiting the individuals in a relationship, but are instead primarily used to address third parties. Where individuals use social media to promote their partner instrumentally to highlight that they are in a relationship, rather than aiming to satisfy their partner's needs directly, it follows that such behaviors may not lead to a greater sense of support in relationships, consistent with present findings. This may also account for the negative correlation observed between public displays of contact and reduced relationship conflict within the current study; where individuals choose to present a positive image of their relationship with their partner to support their own ends [30], a consequence of this could be that their partner also feels more appreciated. Whilst this may hypothetically serve to reduce conflict, online public displays of partnership appear to show no association with relationship depth within the current study, indicating that the interpersonal bond shared by couples is not related to the publically shared content they chose to present via social media.

The use of social media for partner surveillance was positively correlated with greater social support and a greater sense of relationship depth, but was not related to relationship conflict. Moreover a greater sense of online jealousy and insecurity within participants' relationships was also associated with greater perceived relationship depth. These findings appear to contradict previous research which found surveillance on social media to be associated with a dissatisfying relationship [12]. A possible corollary to the current pattern of results might be the use of online mate-retention tactics by participants [7] which are used to 'guard' against potential rivals where a partner is particularly invested in their relationship. Individuals who care more about their partner are more likely to experience online jealousy within their relationship if the feel their relationship could be threatened by external factors [1]. This may provide an explanation as to why individuals who experience greater online jealousy, can also feel a greater sense of depth within their relationship. 
Results from the current study showed a positive association between disinterest in participants' attitudes towards their partner's social media use and feelings of relationship conflict, and a negative association with relationship depth. General perceptions of relationship quality are thought to be derived from a set of expectations that individuals hold about the perceived assistance, commitment and acceptance they receive from their partner [22]. The impact of these expectations on the relationship depends on the values of both parties involved, and not only affects the individual's experience of the relationship but also influences their interactions within the relationship [21]. It follows that a person whose values communicate disinterest about their partner's online actions, where these are dissimilar to the partner's own expectations about the use of social media, may be more likely to experience conflict within their relationship and the bond within the relationship itself may be perceived as less emotionally deep.

\section{CONCLUSION}

The findings of this study provide partial support for the idea that social media platforms may provide an effective mechanism to support and maintain long-distance romantic relationships, which can compensate for the absence of face-to-face contact. However, the overall frequency of social media use was not an important factor in maintaining a satisfying relationship, whether couples were long-distance, geographically close or living together. In addition, social media use was not effective as a means of reducing relationship conflict in any form of relationship. Constant access to social media might result more readily in the use of communication media to facilitate arguments, or for couples to misinterpret each other's intentions. Further research is therefore needed to examine the potential loss of communication effectiveness via social media and impact this may have on relationship quality.

\section{References}

1. Barelds, D., P., H. \& Barelds-Dijkstra. (2007). Relations between Different Types of Jealousy and Self and Partner Perceptions of Relationship Quality. Clinical Psychology and Psychotherapy, 14(3), 176-188. doi:10.1002/cpp.532

2. Belus, J. M., Pentel, K. Z., Cohen, M. J., Fischer, M. S. \& Baucom, D., H. (2018). Staying Connected: An Examination of Relationship Maintenance Behaviors in Long-Distance Relationships. Marriage \& Family Review. doi:10.1080/01494929.2018.1458004

3. Billedo, C., J., Kerkhof, P., \& Finkenauer. (2015). The Use of Social Networking Sites for Relationship Maintenance in Long-Distance Relationships and Geographically Close Romantic Relationships. Cyberpsychology, Behavior, and Social Networking, 8(3), 152-157. doi:10.1089/cyber.2014.0469

4. Bowe, G. (2010). Reading romance: The impact Facebook rituals can have on a romantic relationship. Journal of comparative research in anthropology and sociology, (2), 61-77. 
5. Braiker, H., B., \& Kelley, H., H. (1979). Conflict in the Development of Close Relationships. In R. L. Burgess \& T. L. Huston (Eds.), Social Exchange in Developing Relationships (pp. 135-167). University Park, Pennsylvania, US: Academic Press Inc.

6. Brandtzæg, P., B. \& Heim, J. (2009). Why People Use Social Networking Sites. In: Ozok A.A., Zaphiris P. (eds) Online Communities and Social Computing. OCSC 2009. Lecture Notes in Computer Science, Vol 5621. Springer, Berlin, Heidelberg. doi:10.1007/978-3642-02774-1

7. Brem, M. J., Spiller, L. C., \& Vandehey, M. A. (2015). Online mate-retention tactics on Facebook are associated with relationship aggression. Journal of interpersonal violence, 30(16), 2831-2850. doi: 10.1177/0886260514554286

8. Coyne, S., M., Stockdale, L., Busby, D., Iverson, B., \& Grant, D., M. (2011). “I luv u :)!” A Descriptive Study of the Media Use of Individuals in Romantic Relationships. Interdisciplinary Journal of Applied Family Science, 60(2), 150-162. doi:10.1111/j.17413729.2010.00639.x

9. Dainton, M. \& Aylor, B. (2002). Patterns of communication channel use in the maintenance of long-distance relationships, Communication Research Reports, 19:2, 118-129, DOI: $10.1080 / 08824090209384839$

10. Dargie, E., Blair, K., L., Goldfinger, C., \& Pukall, C., F. (2014). Go Long! Predictors of Positive Relationship Outcomes in Long-Distance Dating Relationships. Journal of Sex and Marital Therapy, 41(2), 181-202. doi:10.1080/0092623X.2013.864367

11. Du Bois, S. N., Sher, T. G., Grotkowski, K., Aizenman, T., Slesinger, N., \& Cohen, M. (2016). Going the distance: Health in long-distance versus proximal relationships. The Family Journal, 24(1), 5-14. doi:10.1177/1066480715616580

12. Elphinston, R. A., \& Noller, P. (2011). Time to face it! Facebook intrusion and the implications for romantic jealousy and relationship satisfaction. Cyberpsychology, Behavior, and Social Networking, 14, 631-635. doi:10.1089/cyber.2010.0318

13. Hampton, A., J., Rawlings, J., Treger, S., \& Sprecher, S. (2015). Channels of ComputerMediated Communication and Satisfaction in Long-Distance Relationships. Interpersona: An International Journal on Personal Relationships, 11(2), 171-187. doi:10.5964/ijpr.v11i2.273

14. Holt, P. A., \& Stone, L. S. (1988). Needs, coping strategies, and coping outcomes associated with long-distance relationships. Journal of College Student Development, 29, 136141.

15. Juhasz, A. \& Bradford, K. (2016) Mobile Phone Use in Romantic Relationships, Marriage \& Family Review, 52:8, 707-721, DOI: 10.1080/01494929.2016.1157123

16. Lee, Y., Chang, C., Lin, Y., \& Cheng, Z. (2014). The dark side of smartphone usage: Psychological traits, compulsive behavior and technostress. Computers in Human Behavior, 31, 373-383. doi:10.1016/j.chb.2013.10.047

17. Mansson, D., H., \& Myers, S., A. (2011). An Initial Examination of College Students' Expressions of Affection through Facebook. Southern Communication Journal, 76(2), 155 168. doi:10.1080/10417940903317710

18. Muise, A., Christofides, E., \& Desmarais, S. (2009). More Information than You Ever Wanted: Does Facebook Bring Out the Green-Eyed Monster of Jealousy? CyberPsychology \& Behavior, 12(4), 441-444. doi:10.1089/cpb.2008.0263

19. Pierce, G., R., Sarason, I., G., \& Sarason, B., R. (1991). General and Relationship-Based Perceptions of Social Support: Are Two Constructs Better Than One? Journal of Personality and Social Psychology, 61(6), 1028-1039. doi:10.1037/0022-3514.61.6.1028 
20. Roberts, A., \& Pistole, M., C. (2011). Long-distance and proximal romantic relationship satisfaction: Attachment and closeness predictors. Journal of College Counseling, 12, 5-17. doi:10.1002/j.2161-1882.2009.tb00036.x

21. Sarason, I., G., Pierce, G., R., \& Sarason, B., R. (1990). Social Support and Interactional Processes: A Triadic Hypothesis. Journal of Social and Personal Relationships, 7(4), 495506. doi:10.1177/0265407590074006

22. Sarason, B., R., Shearin, E., N., Pierce, G., R., Sarason, I., G. (1987). Interrelations of social support measures: Theoretical and practical implications. Journal of Personality and Social Psychology, 52(4), 813-832.

23. Stafford, L. (2005). Maintaining Long-Distance and Cross-Residential Relationships. New York: Routledge, https://doi.org/10.4324/9781410611512

24. Stafford, L., \& Merolla, A., J. (2007). Idealization, reunions, and stability in long-distance relationships. Journal of Social and Personal Relationships, 24(1), 37-54. doi: $10.1177 / 0265407507072578$

25. Stewart, M., C., Dainton, M., \& Goodboy, A., K. (2014). Maintaining Relationships on Facebook: Associations with Uncertainty, Jealousy, and Satisfaction. Communication Reports, 27(1), 13-26. doi:10.1080/08934215.2013.845675

26. Tokunaga, R., S. (2011). Social networking site or social surveillance site? Understanding the use of interpersonal electronic surveillance in romantic relationships. Computers in Human Behavior, 27(2), 705-713. doi:10.1016/j.chb.2010.08.014

27. Turkle, S. (2017). Alone together: Why we expect more from technology and less from each other. New York: Basic Books.

28. Turner, M., Love, S. \& Howell, M. (2008). The importance of mobile telephone communication medium to the maintenance of social relationships. AHFE International (2nd International Conference on Applied Human Factors and Ergonomics), Las Vegas, USA, $14^{\text {th }}$ $17^{\text {th }}$ July.

29. Utz, S. (2007). Media use in long-distance friendships. Information, Communication \& Society, 10: 5, 694 - 713. DOI: 10.1080/13691180701658046

30. Zhao, X., Sosik, V., S., \& Cosley, D. (2012). It's complicated: how romantic partners use facebook. Paper presented at the SIGCHI Conference on Human Factors in Computing Systems. Retrieved from https://dl.acm.org/citation.cfm?id=2207788 